\title{
Importance of the First Postoperative Year in the Prognosis of Elderly Colorectal Cancer Patients
}

\author{
J. W. T. Dekker, MD ${ }^{1}$, C. B. M. van den Broek, MD'1 E. Bastiaannet, MSc ${ }^{1,2}$, L. G. M. van de Geest, MSc $^{3}$, \\ R. A. E. M. Tollenaar, $\mathbf{P h D}^{1}$, and G. J. Liefers, $\mathbf{P h D}^{1}$ \\ ${ }^{1}$ Department of Surgery, Leiden University Medical Centre, Leiden, The Netherlands; ${ }^{2}$ Department of Gerontology and \\ Geriatrics, Leiden University Medical Centre, Leiden, The Netherlands; ${ }^{3}$ Comprehensive Cancer Centre West, Leiden, The \\ Netherlands
}

\begin{abstract}
Background. Elderly colorectal cancer patients have worse prognosis than younger patients. Age-related survival differences may be cancer or treatment related, but also due to death from other causes. This study aims to compare population-based survival data for young ( $<65$ years), aged ( $65-74$ years), and elderly ( $\geq 75$ years) colorectal cancer patients.

Methods. All patients operated for stage I-III colorectal cancer between 1991 and 2005 in the western region of The Netherlands were included. Crude survival, relative survival, and conditional relative survival curves, under the condition of surviving 1 year, were made for colon and rectal cancer patients separately. Furthermore, 30-day, 1-year, and 1-year excess mortality data were compared.

Results. A total of 9,397 stage I-III colorectal cancer patients were included in this study. Crude survival curves showed clear survival differences between the age groups. These age-related differences were less prominent in relative survival and disappeared in conditional relative survival (CRS). Only in stage III disease did elderly patients have worse CRS than young patients. Furthermore, significant age-related differences in 30-day and 1-year excess mortality were found. Thirty-day mortality vastly underestimated 1-year mortality for all age groups.

Conclusions. Elderly colorectal cancer patients who survive the first year have the same cancer-related survival as
\end{abstract}

(C) The Author(s) 2011. This article is published with open access at Springerlink.com

First Received: 14 November 2010;

Published Online: 29 March 2011

G. J. Liefers, $\mathrm{PhD}$

e-mail: G.J.Liefers@lumc.nl younger patients. Therefore, decreased survival in the elderly is mainly due to differences in early mortality. Treatment of elderly colorectal cancer patients should focus on perioperative care and the first postoperative year.

The number of elderly people in the population and the incidence of colorectal cancer are increasing. Therefore, it is to be expected that the number of elderly colorectal cancer patients will further increase. Various populationbased studies show that survival of elderly colorectal cancer patients is worse compared with younger patients. Differences in survival by age group in colorectal cancer may be explained by variations in tumor factors, patient characteristics, and therapy. Elderly colorectal cancer patients tend to have more advanced disease stage. ${ }^{1}$ Besides, they have more comorbidity and are treated less aggressively than their younger counterparts. ${ }^{2}$ Comorbidity influences surgical eligibility and other treatment options. ${ }^{3}$ Furthermore, it represents a greater risk of non-cancerrelated mortality. Elderly patients less frequently receive adjuvant chemotherapy and more often discontinue treatment before completion. ${ }^{4}$

Notwithstanding all these differences, several studies found similar disease-specific survival for elderly and young colorectal cancer patients. ${ }^{5-7}$ This would indicate that the excess mortality in elderly colorectal cancer patients is due to competing causes of death. To gain better insight into survival differences between age groups, the present study aims to compare population-based survival data of colorectal cancer patients for different age groups. It considers not only overall and relative survival but also conditional relative survival under the condition of surviving 1 year. Furthermore, this study focuses on agerelated differences in 30-day and 1-year mortality. 


\section{PATIENTS AND METHODS}

Patients were selected from the regional cancer registry of the Comprehensive Cancer Centre West (CCCW) covering the western part of The Netherlands. The nationwide Dutch Network and Registry of Histo- and Cytopathology (PALGA) regularly submits reports of all diagnosed malignancies to the cancer registries. The national hospital discharge databank, which receives discharge diagnoses of admitted patients from all Dutch hospitals, completes case ascertainment. After notification, trained registry personnel collect data on diagnosis, staging, and treatment from medical records, including pathology and surgery reports, using the registration and coding manual of the Dutch Association of Comprehensive Cancer Centers. Cancer registry data show actual variations in patterns of staging, treatment, and survival by age and therefore offer scope for improvement of care and for creating guidelines, in addition to randomized clinical trials. ${ }^{8}$

From the regional cancer registry, patients diagnosed between 1991 and 2005 with their first, primary, stage I, II or III colon or rectal cancer who were surgically treated were selected. Vital status was established either directly from the patient's medical record or through linkage of cancer registry data with the municipal population registries which record information on their inhabitants' vital status. Stage was based on pathological information; clinical information was used if pathology data were missing.

\section{Statistics}

Patients were divided into younger than 65 years, 65-74 years, and 75 years and older. Differences between characteristics were tested with chi-squared tests. Overall survival was calculated with death due to any cause as event. Relative survival is the preferred way to describe the prognosis of elderly cancer patients, as it takes into account the risk of dying from causes other than the disease of interest. ${ }^{8}$ Relative survival was calculated by the Hakulinen method as the ratio of the survival observed among the cancer patients and the survival that would have been expected based on the corresponding (age, sex, and year) general population. National life tables were used to estimate expected survival. Conditional relative survival was calculated for patients who survived the first year. Relative excess risks of death (RER) were estimated using a multivariate generalized linear model with a Poisson distribution, based on collapsed relative survival data, using exact survival times. Finally, 30-day and 1-year overall mortality were calculated as well as the 1-year excess mortality as (observed - expected deaths)/(number of patients).

\section{RESULTS}

From 1 January 1991 through 31 December 2005 in the CCCW region 9,611 stage I-III colorectal cancer patients were diagnosed and 9,397 (97.8\%) were operated, being 6,405 patients with colon cancer and 2,992 with rectal cancer. These patients had median age of 72 years (range 7-100 years) for colon cancer and 69 years (range 18-98 years) for rectal cancer patients. Patient characteristics according to age group for colon and rectum separately are shown in Table 1 . The percentage of female patients was significantly higher in the oldest age groups, especially for colon cancer patients. The number of treated colon cancer patients increased over the years. Tumor grade was evenly divided for rectal cancer but not for colon cancer patients, with more grade III in the elderly. In this cohort, younger patients had higher tumor stage than the elderly, although the percentage of patients with unknown stage of disease was higher in the elderly (data not shown). Use of adjuvant chemotherapy decreased with advancing age groups. Radiotherapy for rectal cancer patients was comparable for the young and aged groups and was lower in the elderly group.

Figure 1 shows survival curves for overall survival (a), relative survival (b), and conditional relative survival (c) for colon and rectal cancer patients in the different age groups. Differences in survival between age groups for colorectal cancer patients disappeared when a correction was made for death from other causes under the condition of surviving 1 year. As shown in Table 2, the elderly patients had a RER of 1.6 [95\% confidence interval (CI) $1.4-1.9 ; P<0.001]$ as compared with the young patients for colon cancer and $1.4(95 \%$ CI $1.2-1.7 ; P<0.001)$ for rectal cancer. When relative survival was calculated for patients who survived the first year, relative excess risks were around 1.0 (RER 1.1, $P=0.2$ for colon; RER 1.1, $P=0.3$ for rectal cancer). Going into more detail by considering different stages, a significant difference in conditional relative survival remained for stage III patients for both colon and rectal cancer.

Table 3 shows overall 30-day, 1-year, and 1-year excess mortality according to type of tumor in reference to baseline factors. Gender was a significant factor for first-year mortality in rectal cancer, with more male patients dying. Age was the most significant factor for all three mortality endpoints for both colon and rectal cancer patients. Tumor grade did not influence 30-day mortality but was a significant factor for 1-year mortality for both colon and rectal cancer patients. Tumor stage also influenced 30-day mortality for colon cancer patients, but not for rectal cancer patients. Thirty-day and 1-year mortality rates decreased over the years (data not shown). For colon cancer patients this was only significant $(P<0.05)$ for 1 -year mortality 
TABLE 1 Characteristics of patients operated for colon and rectal cancer diagnosed in the period 1991-2005 according to age

\begin{tabular}{|c|c|c|c|c|c|c|c|c|}
\hline & \multicolumn{4}{|l|}{ Colon cancer } & \multicolumn{4}{|l|}{ Rectal cancer } \\
\hline & $\begin{array}{l}<65.0 \text { years, } \\
\text { number }(\%)\end{array}$ & $\begin{array}{l}65-74 \text { years, } \\
\text { number }(\%)\end{array}$ & $\begin{array}{l}\geq 75 \text { years, } \\
\text { number }(\%)\end{array}$ & $\begin{array}{l}P- \\
\text { Value }\end{array}$ & $\begin{array}{l}<65.0 \text { years, } \\
\text { number }(\%)\end{array}$ & $\begin{array}{l}65-74 \text { years, } \\
\text { number }(\%)\end{array}$ & $\begin{array}{l}\geq 75 \text { years, } \\
\text { number }(\%)\end{array}$ & $\begin{array}{l}P- \\
\text { Value }\end{array}$ \\
\hline \multicolumn{9}{|l|}{ Sex } \\
\hline Male & $889(51.1)$ & $964(50.3)$ & $1,123(40.8)$ & \multirow[t]{2}{*}{$<\mathbf{0 . 0 0 1}$} & 603 (57.6) & $513(57.5)$ & 523 (49.7) & \multirow[t]{2}{*}{$<\mathbf{0 . 0 0 1}$} \\
\hline Female & 851 (48.9) & 952 (49.7) & $1,626(59.2)$ & & 444 (42.4) & $379(42.5)$ & $530(50.3)$ & \\
\hline \multicolumn{9}{|l|}{ Year } \\
\hline 1991-1995 & $539(31.0)$ & 624 (32.6) & $831(30.2)$ & \multirow[t]{3}{*}{0.02} & 307 (29.3) & $295(33.1)$ & $342(32.5)$ & \multirow[t]{3}{*}{0.2} \\
\hline 1996-2000 & $531(30.5)$ & $642(33.5)$ & $930(33.8)$ & & $326(31.1)$ & $281(31.5)$ & 343 (32.6) & \\
\hline 2001-2005 & $670(38.5)$ & $650(33.9)$ & $988(36.0)$ & & 414 (39.6) & $316(35.4)$ & 368 (34.9) & \\
\hline \multicolumn{9}{|l|}{ Grade } \\
\hline Grade I & $123(7.1)$ & $129(6.7)$ & $184(6.7)$ & \multirow[t]{4}{*}{0.02} & $62(5.9)$ & 44 (4.9) & $56(5.3)$ & \multirow[t]{4}{*}{0.4} \\
\hline Grade II & $1,150(66.1)$ & $1,326(69.2)$ & $1,808(65.8)$ & & $720(68.8)$ & $652(73.1)$ & 768 (72.9) & \\
\hline Grade III & $284(16.3)$ & $276(14.4)$ & $505(18.3)$ & & $169(16.1)$ & 122 (13.7) & 149 (14.2) & \\
\hline Unknown & $183(10.5)$ & $185(9.7)$ & $252(9.2)$ & & $96(9.2)$ & $74(8.3)$ & $80(7.6)$ & \\
\hline \multicolumn{9}{|l|}{ Stage } \\
\hline Stage I & 317 (18.2) & $386(20.1)$ & 476 (17.3) & \multirow[t]{3}{*}{$<0.001$} & $310(29.6)$ & 333 (37.3) & $380(36.1)$ & \multirow[t]{3}{*}{$<\mathbf{0 . 0 0 1}$} \\
\hline Stage II & 782 (44.9) & $902(47.1)$ & $1,459(53.1)$ & & $318(30.4)$ & $285(32.0)$ & $363(34.5)$ & \\
\hline Stage III & 641 (36.9) & $628(32.8)$ & 814 (29.6) & & 419 (40.0) & 274 (30.7) & $310(29.4)$ & \\
\hline \multicolumn{9}{|l|}{ Treatment } \\
\hline Only surgery & $1,219(70.1)$ & $1,610(84.0)$ & 2,661 (96.8) & \multirow[t]{5}{*}{$<\mathbf{0 . 0 0 1}$} & 447 (42.7) & $471(52.8)$ & 750 (71.2) & \multirow[t]{5}{*}{$<\mathbf{0 . 0 0 1}$} \\
\hline Surgery + RT & $12(0.7)$ & $18(0.9)$ & $4(0.2)$ & & 449 (42.9) & 370 (41.5) & $295(28.0)$ & \\
\hline Surgery + CT & 504 (28.9) & $287(15.0)$ & $84(3.0)$ & & $68(6.5)$ & $34(3.8)$ & $7(0.7)$ & \\
\hline Surgery + CT + RT & $5(0.3)$ & $1(0.1)$ & $0(0.0)$ & & $83(7.9)$ & $17(1.9)$ & $1(0.1)$ & \\
\hline Overall & $1,740(27.2)$ & $1,916(29.9)$ & 2,749 (42.9) & & $1,047(35.0)$ & $892(29.8)$ & $1,053(35.2)$ & \\
\hline
\end{tabular}

$R T$ radiotherapy, $C T$ chemotherapy

rates for all age groups (lowest RER 0.94). For rectal cancer patients, 30-day mortality was significantly reduced $(P<0.01)$ for the elderly (RER 0.89). One-year mortality for the young and aged patients (lowest RER 0.93) was significantly improved $(P=0.03)$, however not for the elderly patients $(P=0.3$; RER 0.98$)$.

\section{DISCUSSION}

Crude survival is a solid outcome measure that shows evident age-related differences. However, crude survival will overestimate the impact of cancer on survival, because it also includes mortality due to other causes. To adjust for this, relative survival is used, defined as the ratio of observed to expected survival. This reduces age-related differences in colorectal cancer survival. However, the results of age-related relative survival are still largely influenced by early mortality (defined as mortality in the first postoperative year). Postoperative complications are a more probable cause for early mortality than the colorectal cancer itself in stage I-III patients (who, in general, had curative surgery). Therefore, to get a clear image of the impact of colorectal cancer on survival for different age groups, we used conditional relative survival under the condition of surviving 1 year. As a result, age-related differences in survival disappeared, indicating that probably colorectal cancer itself is not the main cause of age-related differences in survival. This is in line with earlier studies that found no age-related differences in cancer-specific survival. ${ }^{5-7}$ However, this remains intriguing, since many papers indicate that differences in survival between the young and the elderly can be attributed to undertreatment in the elderly. ${ }^{1,9}$ Our study confirms these variations in treatment and that conditional survival in stage III patients is indeed significantly worse in the elderly. Nonetheless, the excess mortality in the first postoperative year was the main determining factor for age-related survival differences.

\section{Postoperative Mortality}

The 30-day mortality rates for the different age groups in the present study are in accordance with earlier findings by other studies. ${ }^{10,11}$ However, the most striking finding of this analysis is the fact that 30-day mortality vastly underestimates 1-year mortality for all age groups. 


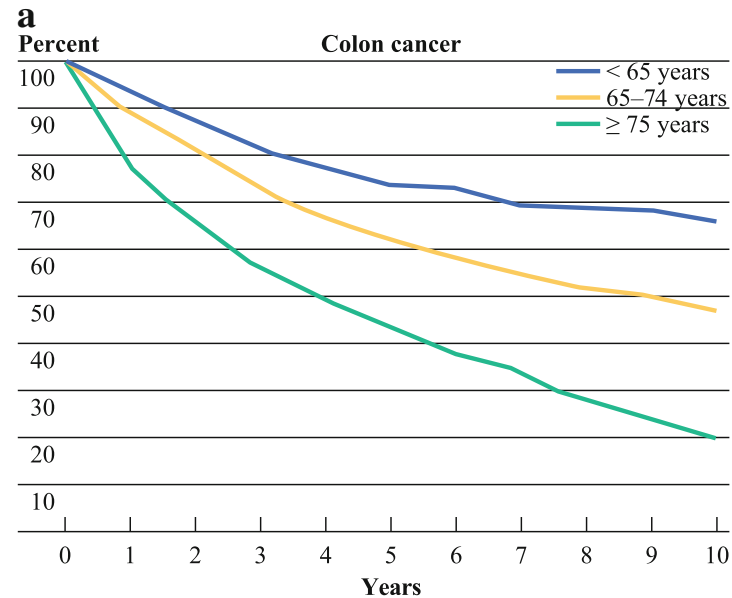

b

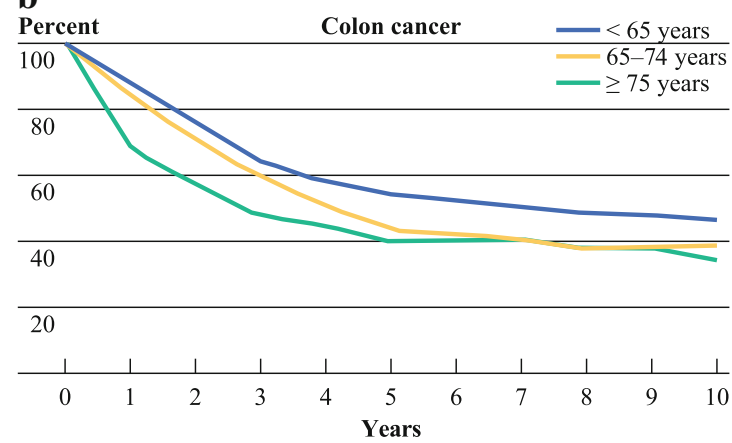

c

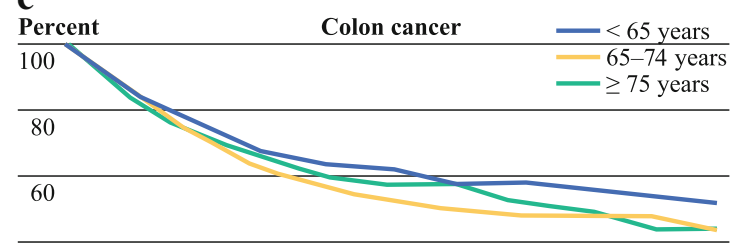

40

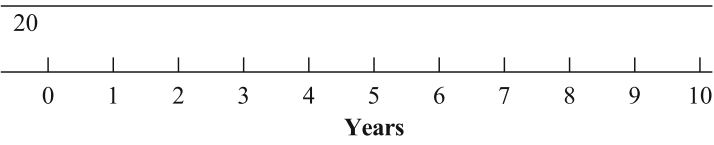

FIG. 1 a Overall survival according to age for stage I-III patients operated for colon and rectal cancer. b Relative survival according to age for stage I-III patients operated for colon and rectal cancer.

Apparently, the impact and consequences of treatment have a prolonged effect on mortality. This effect is very strong even for patients in the youngest group. With increasing age, also the excess mortality increases. It has been shown earlier that, with increasing age, not only mortality but also postoperative morbidity increases. ${ }^{12-14}$ Furthermore, Manku et al. showed that in-hospital complications had prognostic significance. ${ }^{15}$ In 517 patients who underwent noncardiac surgery, they found that postoperative complications caused mortality up to 3 months after surgery, with a sustaining effect on survival. Greenblatt et al. studied stage I-III colon cancer patients from the Surveillance,
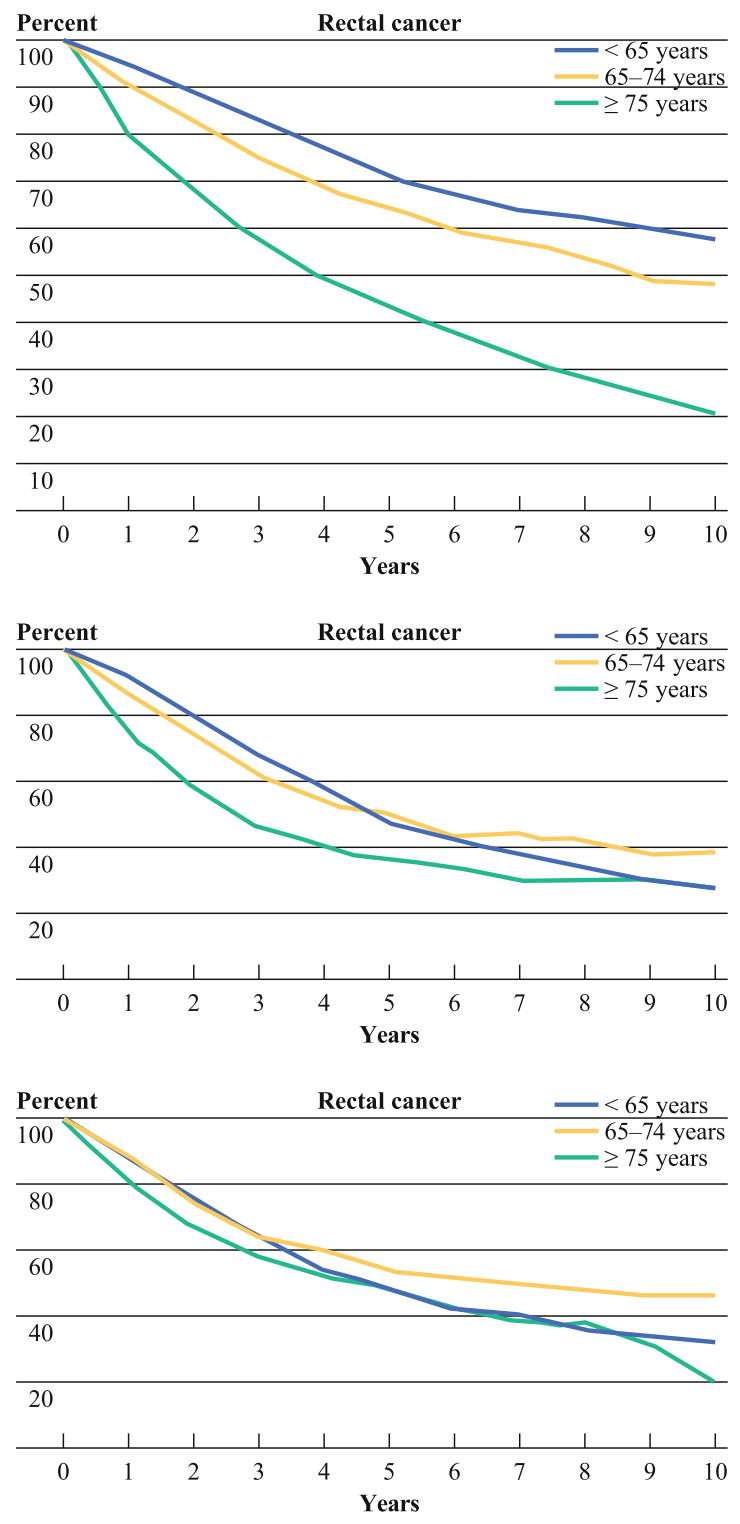

c Conditional relative survival (conditioning on patients who survived 1 year) according to age for stage I-III patients operated for colon and rectal cancer

Epidemiology, and End Results-Medicare database and found that readmission was strongly associated with 1-year mortality. ${ }^{16}$ The same variables that predicted readmission in this study also predicted 1-year mortality (male gender, comorbidity, emergent admission, prolonged hospital stay, blood transfusion, ostomy, and discharge to a nursing home). Kunitake et al. showed that patients older than 80 years were readmitted almost twice as much as patients younger than 65 years. ${ }^{17}$ Furthermore, in their study, $75 \%$ of readmissions were not related to the surgery itself. With the present study, all these studies seem to imply that, for a significant number of patients, the assault of surgery has 
TABLE 2 Relative and conditional survival of operated stage I-III patients

\begin{tabular}{|c|c|c|c|c|c|c|c|c|}
\hline \multirow[t]{2}{*}{ Colon cancer } & \multicolumn{2}{|l|}{ All stages } & \multicolumn{2}{|l|}{ Stage I } & \multicolumn{2}{|l|}{ Stage II } & \multicolumn{2}{|l|}{ Stage III } \\
\hline & $\mathrm{RS}$ & $\mathrm{CS}$ & RS & $\mathrm{CS}$ & $\mathrm{RS}$ & $\mathrm{CS}$ & RS & $\mathrm{CS}$ \\
\hline$<65$ years & Ref & Ref & Ref & Ref & Ref & Ref & Ref & Ref \\
\hline 65-74 years & $1.2(1.0-1.4)$ & $1.2(1.0-1.4)$ & $1.2(0.6-2.4)$ & $1.2(0.6-2.5)$ & $1.2(0.9-1.5)$ & $1.3(1.0-1.8)$ & $1.4(1.2-1.7)$ & $1.3(1.0-1.6)$ \\
\hline$P$-Value & 0.01 & 0.03 & 0.7 & 0.5 & 0.2 & 0.04 & $<0.001$ & 0.02 \\
\hline $75+$ years & $1.6(1.4-1.9)$ & $1.1(0.9-1.4)$ & $1.2(0.5-2.8)$ & N.A. & $1.8(1.4-2.2)$ & $1.3(0.9-1.8)$ & $2.0(1.6-2.3)$ & $1.4(1.1-1.8)$ \\
\hline$P$-Value & $<0.001$ & 0.2 & 0.7 & 0.99 & $<\mathbf{0 . 0 0 1}$ & 0.1 & $<0.001$ & 0.003 \\
\hline \multirow[t]{2}{*}{ Rectal cancer } & \multicolumn{2}{|l|}{ All stages } & \multicolumn{2}{|l|}{ Stage I } & \multicolumn{2}{|l|}{ Stage II } & \multicolumn{2}{|l|}{ Stage III } \\
\hline & $\mathrm{RS}$ & $\mathrm{CS}$ & $\mathrm{RS}$ & $\mathrm{CS}$ & $\mathrm{RS}$ & $\mathrm{CS}$ & $\mathrm{RS}$ & $\mathrm{CS}$ \\
\hline$<65$ years & Ref & Ref & Ref & Ref & Ref & Ref & Ref & Ref \\
\hline 65-74 years & $1.0(0.8-1.2)$ & $0.9(0.7-1.1)$ & $0.8(0.4-1.8)$ & $0.6(0.3-1.5)$ & $1.2(0.8-1.6)$ & $1.1(0.8-1.7)$ & $1.2(0.9-1.5)$ & $1.1(0.8-1.4)$ \\
\hline$P$-Value & 0.8 & 0.2 & 0.6 & 0.3 & 0.4 & 0.6 & 0.1 & 0.6 \\
\hline $75+$ years & $1.4(1.2-1.7)$ & $1.1(0.9-1.4)$ & $1.7(0.8-3.6)$ & $0.3(0.1-7.0)$ & $1.6(1.1-2.2)$ & $1.4(0.9-2.2)$ & $1.8(1.4-2.3)$ & $1.5(1.2-2.0)$ \\
\hline$P$-Value & $<\mathbf{0 . 0 0 1}$ & 0.3 & 0.2 & 0.5 & 0.009 & 0.1 & $<\mathbf{0 . 0 0 1}$ & 0.002 \\
\hline
\end{tabular}

$R S$ relative survival, $C S$ conditional survival, N.A. not addressed due to small numbers

TABLE 3 Overall 30-day and 1-year mortality and relative 1-year mortality rates in percentages according to type of tumor

\begin{tabular}{|c|c|c|c|c|c|c|c|c|}
\hline & \multicolumn{4}{|c|}{ Colon cancer } & \multicolumn{4}{|c|}{ Rectal cancer } \\
\hline & \multicolumn{3}{|c|}{ Overall mortality } & \multirow{2}{*}{$\begin{array}{l}\text { Excess mortality } \\
1 \text { st year }\end{array}$} & \multicolumn{3}{|c|}{ Overall mortality } & \multirow{2}{*}{$\begin{array}{l}\text { Excess mortality } \\
1 \text { st year }\end{array}$} \\
\hline & $N$ & $\leq 30$ days & 1 st year & & $N$ & $\leq 30$ days & 1st year & \\
\hline \multicolumn{9}{|l|}{ Sex } \\
\hline Male & 2,976 & 4.6 & 15.7 & 11.3 & 1,639 & 2.1 & 13.2 & 9.4 \\
\hline Female & 3,429 & 4.1 & 14.5 & 10.9 & 1,353 & 1.3 & 9.9 & 6.9 \\
\hline \multicolumn{9}{|l|}{ Age (years) } \\
\hline$<65$ & 1,740 & 1.4 & 6.8 & 6.1 & 1,047 & 0.2 & 5.1 & 4.4 \\
\hline $65-74$ & 1,916 & 2.4 & 10.8 & 8.5 & 892 & 1.4 & 9.5 & 7.2 \\
\hline$\geq 75$ & 2,749 & 7.5 & 23.2 & 16.0 & 1,053 & 3.7 & 20.1 & 13.1 \\
\hline \multicolumn{9}{|l|}{ Grade } \\
\hline I & 436 & 2.1 & 9.9 & 6.0 & 162 & 3.1 & 8.0 & 4.9 \\
\hline II & 4,284 & 4.4 & 12.6 & 8.5 & 2,140 & 1.8 & 10.2 & 6.6 \\
\hline III & 1,065 & 4.7 & 25.2 & 21.3 & 440 & 1.6 & 22.3 & 19.5 \\
\hline Unknown & 620 & 4.8 & 18.2 & 14.8 & 250 & 1.2 & 8.4 & 5.2 \\
\hline \multicolumn{9}{|l|}{ Stage } \\
\hline I & 1,179 & 1.7 & 8.0 & 4.0 & 1,023 & 1.5 & 7.6 & 3.8 \\
\hline II & 3,143 & 5.0 & 13.5 & 4.0 & 966 & 2.4 & 12.7 & 9.1 \\
\hline III & 2,083 & 4.8 & 21.4 & 4.0 & 1,003 & 1.5 & 14.9 & 12.1 \\
\hline
\end{tabular}

delayed effects that can cause mortality beyond the scope of the surgery.

\section{Stage III Patients}

Only in stage III patients were age-related differences found in conditional relative survival. Here, differences in (neo)adjuvant therapy between the age groups were most apparent. This is in line with earlier studies that show that elderly patients are undertreated. ${ }^{4}$ This undertreatment of elderly patients could explain the age-related differences in conditional relative survival for stage III patients. However, also in stage III patients, first-year mortality remains a crucial factor for survival. The difference in conditional relative survival between young and elderly stage III patients was $10.4 \%$ for colon and $5.6 \%$ for rectal cancer, 
while the differences in 1-year excess mortality rates were $17.2 \%$ and $12.0 \%$, respectively.

\section{Limitations}

An obvious limitation of this study is the lack of information on emergency surgery and comorbidity. Both are associated with increased postoperative complications and mortality. They will not only have had a prominent influence on early mortality for all age groups, but they probably account for the differences between the age groups as well. Elderly patients are more likely to undergo emergency surgery, and also the incidence of comorbidity increases with age. ${ }^{10}$ Nevertheless, the strength of this study is that it shows the essence of age-related survival and early mortality differences in a large population-based cohort.

\section{Clinical Implications}

The results of this study could provide a focus for future studies and have implications for the clinical setting. As age-related differences in mortality are most apparent for the first postoperative year, this is where the focus must be in treating elderly colorectal cancer patients. Although some risk factors may not be modifiable, others relate to care processes. More attention should be given to patient selection and careful preoperative evaluation, followed by medical optimization, proper timing of surgery, and planning of perioperative care. Furthermore, appropriate referral to high-volume or dedicated centers should be considered if it is anticipated that patients will require a higher level of resources and care following surgery. Quality enhancement programs could focus on particular complications. These should not only try to prevent the occurrence of perioperative complications but also focus on early identification and adequate treatment of complications to avoid related mortality. ${ }^{18}$

The excess mortality of the first postoperative year forms a clear indication of the prolonged impact of the perioperative period, especially when complications occur. Therefore, we should anticipate preoperatively the level of functioning after discharge. ${ }^{13}$ The targets of treatment for elderly patients should extend beyond the in-hospital period, and continued attention should be given to comorbidity and complications in the post-hospital period.

The prolonged impact of the perioperative period could also have a profound effect on functional status and quality of life. For elderly patients these issues should be evaluated with care, especially when they have limited life expectancies. However, for the majority of patients, age per se is not a contraindication for surgery, not least because surgery for colorectal cancer is often the best way to ensure palliation.

\section{CONCLUSIONS}

This study can help to comprehend the challenge of treating elderly colorectal cancer patients. When survival data for colorectal cancer are corrected for expected death from other causes and first-year mortality, age differences disappear. Therefore, decreased survival in the elderly is mainly due to differences in early mortality. Only for stage III disease did elderly patients fare worse, probably as a result of less extensive adjuvant treatment. The overall difference between the younger and elderly age groups is that, within the elderly group, there is an excess mortality of about $10 \%$ the first year. Further studies are necessary to elucidate the etiology of these differences and whether they may be modifiable. This study implies that, in treating elderly stage I-III colorectal cancer patients, the focus should be on the perioperative process and the first postoperative year.

OPEN ACCESS This article is distributed under the terms of the Creative Commons Attribution Noncommercial License which permits any noncommercial use, distribution, and reproduction in any medium, provided the original author(s) and source are credited.

\section{REFERENCES}

1. Papamichael D, Audisio R, Horiot JC, et al. 2009. Treatment of the elderly colorectal cancer patient: SIOG expert recommendations. Ann Oncol. 20:5-16.

2. Lemmens VE, Janssen-Heijnen ML, Houterman S, et al. Which comorbid conditions predict complications after surgery for colorectal cancer? World J Surg. 2007;31:192-9.

3. Janssen-Heijnen ML, Maas HA, Houterman S, et al. Comorbidity in older surgical cancer patients: influence on patient care and outcome. Eur J Cancer. 2007;43:2179-93.

4. Muss HB, Biganzoli L, Sargent DJ, et al. Adjuvant therapy in the elderly: making the right decision. J Clin Oncol. 2007;25:1870-5.

5. Vironen J, Kellokumpu S, Andersson LC, et al. Comparison of a peanut agglutinin test and an immunochemical faecal occult blood test in detecting colorectal neoplasia in symptomatic patients. Scand J Clin Lab Invest. 2004;64:140-5.

6. Puig-La CJ, Jr., Quayle J, Thaler HT, et al. Favorable short-term and long-term outcome after elective radical rectal cancer resection in patients 75 years of age or older. Dis Colon Rectum. 2000;43:1704-9.

7. Violi V, Pietra N, Grattarola M, et al. Curative surgery for colorectal cancer: long-term results and life expectancy in the elderly. Dis Colon Rectum. 1998;41:291-8.

8. Louwman WJ, Vulto JC, Verhoeven RH, et al. Clinical epidemiology of breast cancer in the elderly. Eur J Cancer. 2007;43: 2242-52.

9. Aparicio T, Navazesh A, Boutron I, et al. Half of elderly patients routinely treated for colorectal cancer receive a sub-standard treatment. Crit Rev Oncol Hematol. 2009;71:249-57.

10. Colorectal Cancer Collaborative Group. Surgery for colorectal cancer in elderly patients: a systematic review. Lancet. 2000;356: 968-74.

11. Tan JJ, Foo AY, Cheong DM. Colorectal clinical pathways: a method of improving clinical outcome? Asian J Surg. 2005;28: 252-6. 
12. Rutten HJ, den DM, Lemmens VE, et al. Controversies of total mesorectal excision for rectal cancer in elderly patients. Lancet Oncol. 2008;9:494-501.

13. Bentrem DJ, Cohen ME, Hynes DM, et al. Identification of specific quality improvement opportunities for the elderly undergoing gastrointestinal surgery. Arch Surg. 2009;144: 1013-20.

14. Cohen AM. Management of colorectal cancer. Compr Ther. 1990;16:43-50.

15. Manku K, Bacchetti P, Leung JM. Prognostic significance of postoperative in-hospital complications in elderly patients. I. Long-term survival. Anesth Analg. 2003;96:583-9. Table.
16. Greenblatt DY, Weber SM, O'Connor ES, et al. Readmission after colectomy for cancer predicts one-year mortality. Ann Surg. 2010;251:659-69.

17. Kunitake H, Zingmond DS, Ryoo J, et al. Caring for octogenarian and nonagenarian patients with colorectal cancer: what should our standards and expectations be? Dis Colon Rectum. 2010;53:735-43.

18. Birkmeyer JD, Sharp SM, Finlayson SR, et al. Variation profiles of common surgical procedures. Surgery. 1998;124:917-23. 